\title{
TEMPORAL INTERPRETATION OF THE WORLD IN DAGESTANIAN LANGUAGES
}

\author{
Zulaykhat M. Mallaeva \\ Institute of Language, Literature and Art of the Dagestan Federal Research Centre \\ of the Russian Academy of Sciences; (ILLA DFRC RAS), \\ 45, St. M. Gadzhiev, Makhachkala, 367000, Russia \\ Rashidat Sh. Khalidova \\ Dagestan State Pedagogical University (DSPU). \\ 37, St. M. Jaragskogo, Makhachkala, 367000, Russia
}

\begin{abstract}
The article deals with certain aspects of conceptualization of time, predetermined by the national specificity of the world perception. The topicality of the given study is accounted for by the extremely differentiated verbalization of space and time peculiar to the Dagestanian languages.

The aim of the article is to identify the common origin of temporal and spatial vocabulary in the Dagestanian languages. To achieve the goal, the authors used a comparative-typological method, as well as a cognitive approach to reveal the role of national consciousness in conceptualization of time.

The article also examines some aspects of national peculiarities of time conceptualization aimed at finding out the genetic connection between temporal and space vocabulary.

The data under study allows claiming that in the basis of most lexemes with temporal meaning lies a semantic component denoting "space". Temporal lexemes representing cycling time were developed by means of objectivation of the heavenly bodies' movement. Meanwhile temporal vocabulary representing line time was formed by means of semantic conversion which allowed transforming local adverbs onto temporal.

The most important results obtained by the authors are as follows: (a) the conceptualization of time in the Dagestanian languages is realized on the basis of spacial parameters, so the vocabulary of temporal semantics are formed on the basis of spatial vocabulary; $b$ ) the temporal vocabulary of the Dagestanian languages has evolved along the lines of spatial representations $>$ space-time representations $>$ time representations.

The results achieved are important for the cognitive studies of the Dagestanian languages, as well as for the further description of the space and time conceptualization in the world language pictures.
\end{abstract}

Key Words: the Dagestanian languages, conceptualization of time, substance time, spatial representations 


\title{
ЭТНОСПЕЦИФИКА КОНЦЕПТУАЛИЗАЦИИ ВРЕМЕНИ В ДАГЕСТАНСКИХ ЯЗЫКАХ
}

\author{
3.М. Маллаева \\ Институт языка, литературы и искусства им. Г. Цадасы \\ Дагестанского федерального исследовательского центра Российской академии наук, \\ 367000, Россия, г. Махачкала, ул. М. Гаджиева, 45 \\ Р.ШІ. Халидова \\ Дагестанский государственный педагогический университет, \\ 367009, Россия, г. Махачкала, ул. М. Ярагского, 57.
}

\begin{abstract}
Аннотация. В статье анализируются некоторые аспекты концептуализации времени, обусловленные национальной спецификой восприятия окружающего мира. Актуальность исследования определяется тем, что в дагестанских языках представлена специфичная дибференцированная вербализация пространства и времени, обусловленная рядом факторов.

Цель статьи - выявление генетической общности темпоральной и пространственной лексики в дагестанских языках. Для достижения поставленной иели использован сравнительно-типологический метод с привлечением материала как письменных, так и бесписьменных дагестанских языков, и когнитивный подход для определения роли национального сознания в кониептуализации времени.

Анализируемый в статье языковой материал, позволяет утверждать, что в основу большинства лексем с темпоральной семантикой заложен семантический компонент «пространство». Темпоральная лексика, репрезентирующая ииклическое время, развивалась посредством объективизации движения небесных тел. Темпоральная лексика, репрезентирующзая линейное время, бормировалась посредством семантической конверсии, которая позволила превращать локальные наречия в темпоральные.

Наиболее важными из полученных результатов представляются следующие: а) концептуализаиия времени в дагестанских языках осуществляется на основе пространственных параметров, поэтому лексика темпоральной семантики формируется на базе пространственной пексики; б) темпоральная лексика дагестанских языков развивалась по схеме: пространственные представления > пространственно-временные представления > временные представления.

Полученные результать имеют значение для когнитивных исследований дагестанских языков и для дальнейщего описания концептуализации пространства и времени в языковых картинах мира.

Статья адресована тем, кто интересуется кавказскими языками, лингвистической типологией и языковой картиной мира.
\end{abstract}

Ключевые слова: дагестанские языки, кониептуализаиия времени, субстанииональное время, пространственные представления

Л

ингвистическое время, или темпоральность, является языковой универсалией и представляет собой языковую интерпретацию реального времени, поскольку физическое время находит своё отражение, прежде всего, в сознании людей и уже затем выражается в языке. Категория темпоральности имеет сложную внутреннюю структуру и представляет собой многослойное и многоаспектное явление. 
В данной статье предполагается исследовать этноспецифику восприятия и концептуализации времени в близкородственных дагестанских языках ${ }^{1}$. Ещё в начале этого века акад. Г.Г. Гамзатов писал: «Притчей во языцех стало дагестанское многоязычие. Иной из читателей может иронически заметить: вот опять о своей «стране гор и горе языков». Но как быть, если страна эта именно такая, если у неё действительно много гор и много языков, если на относительно небольшой - в 50 тыс. кв. км. - территории этой страны с населением около 2 млн. человек, обитает более 30 народностей, говорящих на разных языках и принадлежащих к различным этноязыковым общностям - кавказской, тюркской, индоевропейской, что составляет около четверти общего числа народностей современной России?» [4, с. 14]. За последние двадцать лет только дагестанских языков эргативной типологии стало намного больше (около сорока языков) по той причине, что даргинский язык, характеризующийся сильной диалектной раздробленностью, рассматривается ныне как группа самостоятельных родственных языков.

Дагестанские языки не только поражают многочисленностью и диалектной раздробленностью, но и привлекают неизменный интерес лингвистов, вследствие специфических особенностей фонетики, грамматики и лексики. Грамматический строй всех дагестанских языков характеризуется наличием большого количества локативных падежей, прегнантно выражающих локализацию и ориентацию объекта в пространстве, и большим количеством временных форм глагола, весьма дискретно дифференцирующих локализацию процесса во времени. Пространство и время, как основополагающие категории бытия, получают в дагестанских языках чрезвычайно дифференцированную вербализацию, что является общим свойством всех дагестанских языков. Различия проявляются в способах и средствах вербализации пространства и времени.

Система лингвистического времени состоит из двух подсистем: процессуального (глагольного) времени и субстанционального (именного) времени. Процессуальное время реализуется финитными и инфинитными формами глагола и является центром лингвистического времени. Глагол в дагестанских языках, по единодушному мнению исследователей, считается наиболее сложной по морфологическому богатству и важной по функциональной нагрузке частью речи. В дагестанских языках представлена богатая, чрезвычайно разветвлённая система времён глагола.

Субстанциональное время представлено наречиями времени и именами существительными с темпоральной семантикой. Оно более наглядно, чем процессуальное время, передаёт разницу в концептуализации реального времени представителями разных культур и традиций. Поэтому в данной статье исследуется именно лексическая концептуализация времени. Разница в концептуализации проявляется как в способах, так и в средствах локализации времени. Общей для всех языков является концептуализация времени посредством различных пространственных параметров. Для репрезентации временных значений язык «объективизирует время» [11], то есть превращает реальное время в некую осязаемую субстанцию, что позволяет «оперировать временем как пространством» [2].

Идея концептуализации времени через пространство признаётся не всеми лингвистами. Так, С.А. Чугунова считает приоритетной для темпоральной семантики «концептуальную структуру, схематично выражаемую как ВРЕМЯ ЕСТЬ ДВИЖЕНИЕ, а не ВРЕМЯ ЕСТЬ ПРОСТРАНСТВО, но не движение вообще, абстрактное движение, а движение собственного тела. Темпоральный опыт неразрывно связан с опытом движения и прежде всего самодвижения, кинестезии, проприоцепции. Специфика двигательной активности человека предопределяет нейрокогнитивные

\footnotetext{
1 Следует разграничивать термины «дагестанские языки» (лингв.) и «языки Дагестана» (геогр.). Термин «дагестанские языки» охватывает только автохтонные горские дагестанские языки (относятся к языкам эргативной типологии), характеризующиеся общностью происхождения, которая проявляется на всех языковых уровнях (фонетическом, морфологическом, синтаксическом и лексическом). По близости родства дагестанские языки делятся на три труппы: 1. Самая многочисленная - аваро-андо-цезская группа - включает аварский язык, 8 андийских языков (андийский, ботлихский, годоберинский, каратинский, ахвахский, багвалинский, тиндинский, чамалинский) и пять цезских языков (цезский, хваршинский, гинухский, бежтинский, гунзибский). 2. Языки лезгинской группы (10 языков) - лезгинский, табасаранский, агульский, рутульский, цахурский, арчинский, крызский, будухский, хиналугский и удинский. 3. В третью группу входят лакский и даргинский языки.

Термин «языки Дагестана», кроме вышеперечисленных, охватывает ещё и другие языки, представленные на территории Дагестана: из тюркских - кумыкский, ногайский, азербайджанский; из славянских - русский, из иранских - татский, из нахских - чеченский.
} 
механизмы темпоральности, которые неотделимы от особенностей человеческого мировосприятия» [13]. Безусловно, человек познаёт окружающий его реальный мир именно через осознание себя и собственного тела. Но разве возможно движение вне пространства? Пространство вербализуется в двух аспектах: покоя (локализация) и движения (ориентация).

Пространственные параметры лежат в основе концептуализации как линейного, так и циклического времени. Объяснить это можно, по всей видимости, тем, что время - абстрактно, не поддаётся зрительному восприятию, поэтому для его отражения человек применяет категории пространства. Пространство (пространственная локализация и ориентация) носит конкретный характер и поддаётся зрительному восприятию. Глаза - это орган первичного восприятия пространства. Но у человека нет такого соматического органа или неврологического аппарата, который бы воспринимал глобальное время. Физическое время неуловимо и неосязаемо, на основании этого факта автор известной монографии «The Structure of Time. Language, meaning and temporal cognition» Вивьен Эванс [15], ставит под сомнение существование времени как объективной реальности, поскольку мы фактически не чувствуем его.

Лингвистически корректной принято считать ситуацию, когда лексическое содержание сферы прошлого определяется исходя из пространственной локализации «позади» субъекта, а сферы будущего - из локализации «перед» субъектом. Происходит это, очевидно, по той причине, что в большинстве языков мира понятия прошлого и будущего структурируются таким образом. Однако это не является универсальной схемой локализации темпоральной семантики на основе пространственных ориентиров. Целый ряд языков использует иные схемы локализации времени на пространственных параметрах. Как показали исследования В. Эванс, на языке аймара, на котором говорят в Чили, в Боливии и в области Перу, относящейся к Андам, иначе структурируют понятия прошлого и будущего. Здесь, чтобы выразить темпоральную семантику сферы будущего, употребляется локализация «позади» субъекта, в то время как прошлое носители языка аймара локализуют «впереди» субъекта, воспринимающего время [15, с. 254].

Такое восприятие времени, на первый взгляд, представляется алогичным. Тем не менее, здесь имеется своя логика: прошлое имеет ясные очертания по той причине, что оно уже было, поэтому прошлое понятно и обозримо, как обозримо то, что находится перед глазами, то есть перед человеком. Будущее не имеет таких чётких очертаний, оно скрыто от глаз и, соответственно, локализуется позади субъекта, воспринимающего мир.

Сопоставляя наречия агульского языка с пространственной семантикой уригь 'вперёд', 'впереди’ и временной семантикой уригъди 'прежде, давно', 3.К. Тарланов выражает недоумение, «как один и тот же корень стал обозначать противоположные значения: ведь значения прежний, давний невозможно как-то свести к значению передний, скорее это полярные значения, ибо прежнее в современном сознании связывается не с предстоящим, а с прошлым, реализуя тем самым семантику, противоположную этимологически первичной. Кстати, так обстоит дело и в других языках, и не только в кавказских, ср., например, в русском вперёд и прежде. Дело в том, что корень уригь изначально выражал не только нахождение впереди, но и предшествование чего-либо чему-либо; то, что предшествовало, становилось прежним, раньше (впереди) пройденным с точки зрения последующего» $[10$, с. 341]. На наш взгляд, значения прежний, давний вполне можно свести к значению передний. Логически это можно обосновать тем, что событие, происходившее в прошлом, в сознании людей имеет ясные очертания, оно обозримо и в любое время может возникнуть перед глазами человека, пережившего эти события. Поэтому прошлое носители дагестанских языков располагают перед субъектом, например: авар. иерекъад «позавчера» (иере «перед»); лезг. вилик юкъуз «позавчера» (вилик «впереди», «перед»).

А будущее, наоборот, не имеет ясных очертаний, оно скрыто от человека, он не видит будущее воочию, поэтому оно располагается позади человека. Аналогичная ситуация наблюдается и в русском языке: предыдущий (прошльй) год, предьдущий (прошльй) месяи, предыдущзая (прошлая) неделя. В русском языке временной отрезок или событие, имевшее место в прошлом, может мыслиться как локализованное перед субъектом, например: предыдущее мероприятие, предыдущая неделя и др. Хотя это не является правилом, поскольку перед субъектом может быть 
локализовано не только прошлое, но и будущее: предстоящее мероприятие, предстоящая неделя и др. Представляет интерес исследование русской темпоральной картины мира в совокупности взаимодействия онтологических и субъективных факторов и с учётом присущей русскому языку специфики концептуализация времени в монографии Т.В. Булыгиной и А.Д. Шмелёва [3].

На различные когнитивные особенности отражения действительности в типологически разных языках, реализующихся в намёках на прошлое и намёках на будущее, указывал известный отечественный лингвист Г.П. Мельников [8, с. 110-111]. В отличие от сторонников известной гипотезы Сепира-Уорфа, возводящих различия в концептуализации внешнего мира к специфике строя языка, Г.П. Мельников считал, что эти различия формируются как следствие накопления индивидуального и социального опыта взаимодействия людей с этим миром, и выбор тех или иных наиболее удобных в определённых условиях способов выражения элементов этого опыта, как содержание знаков языка в актах общения, существенного воздействия на выражаемое содержание, то есть на мировоззрение носителей языка, оказать не может [9, с. 465].

Подтверждением тому может служить концептуализация времени в дагестанских языках эргативной типологии. Одни из них для вербализации времени используют горизонтальную локализацию (корреляция «впереди» «позади»), другие - вертикальную (корреляция «над» «под»). Вертикальная концептуализация времени характерна для дагестанских языков, носители которых проживают высоко в горах. В них сфера будущего представляется локализованной «над» субъектом, в то время как сфера прошлого представляется локализованной «под» субъектом, воспринимающим время. Например: в аварском языке тІадеяльльул означает «в следующем году». Корень данной лексемы представлен наречием mIad «на, наверху, над», mIade «наверх», -льльул - формант генитива, выражающий семантику принадлежности, например:

Гьеб тІехь mIade босе. «Эту книгу наверх подними».

ТІадеяльльул мунги цадахъ вачина. «В следующем году и тебя с собой возьмём».

Лексема гъоркьисса означает «в прошлом году», здесь корень представлен наречием гъоркь «внизу», «под», -cca - формант одного из локативных падежей, выражающий семантику удаления от ориентира, например:

Къалам бакІида гъоркве бортана. «Карандаш упал под стул».

Гъоркьисса магІарда гІемер гІазу бана. «В прошлом году в горах выпало много снега».

Носители близкородственных каратинского и чамалинского языков также локализуют наступающий год над субъектом: карат. каба «наверх» $\rightarrow$ кабарис решин «следующий год», букв. «верхний год», кабарельа «в следующем году»; чамал. ахи «наверх» $\rightarrow$ ахили «в следующем году» и т.д.

Как видим, лексика, репрезентирующая субстанциональное время в дагестанских языках, генетически восходит к лексике с пространственной семантикой. Категории пространства и времени считаются универсальными способами вербализации мира, поэтому картины мира языков различных культур основываются на этих философских категориях [16; 14].

Семантический компонент «пространство» или «пространственное перемещение» составляет основу некоторых единиц темпоральной лексики, репрезентирующих циклическое время. В русском языке одна и та же лексема «месяц» репрезентирует два значения: небесное тело «месяц (луна)» и единицу измерения времени «месяц (календарный)». Этот факт свидетельствует о том, что для измерения циклического времени носители русского языка, как и абсолютное большинство народов, пользовались небесным телом. Аналогичную семантику репрезентирует в английском языке лексема month, в немецком Monat (> Mond). В дагестанских языках также одной лексемой передаются два значения «месяц (луна)» и «месяц (календарный)», например: авар. моцІиІ, дарг. бадз, лак. барз, лезг. варз, таб. вара, арч. баи, чамал. босIcI, карат. бориІиІо, ахв. боичцІо и т.д. Перечисленные выше дагестанские лексемы относятся к общекавказскому хронологическому уровню [12, с. 95].

В некоторых дагестанских языках слова, обозначающие различные части светового дня, этимологически восходят к слову «солнце». В даргинском языке слово бархІи имеет два значения: «солнце» и «день». Первым значением слова бархІи было «солнце», затем на основе метафорического переноса данная лексема приобрела значение «день». 
В лезгинском языке слова югъ «день» и рагъ «солнце» имеют единый корень -гъ. В аварском языке также слова къо «день» и бакъ «солнце» имеют единый корень -къ. Носители аварского языка структурируют световой день по положению солнца на небе: къад (кбаде) «днём», «в полдень», букв. (ба-къ «солнце» + $а д$ «наверху» = «солнце наверху (в зените)»), бакъанида «под вечер», букв. «солнце уходящее время», бакъанимех «предвечерняя пора», букв. «солнце уходящее время», къаденахъе «пополудни», «после полудня», букв. «после того, как солнце было в зените» [6, с. 42; 7, c. 82].

В каратинском языке названия некоторых частей суток имеют материальную общность с корневой морфемой, обозначающей «солнце», например: льайл «день», лъайкьIa «полдень» > ми-лье «солнце», льайл рабил «к полудню» (льайл «день» + рабил «пока придёт»), льайкьIа хигал «после полудня» (льайкьIа «днём» + хигал «после, сзади»), льайкьIа хидихъ «пополудни», «после полудня» (льайкьІа «днём» +хидихъ «назад»).

Наиболее наглядно этнические особенности концептуализации времени проявляются в способах образования темпоральных наречий. В большинстве дагестанских языков локальные наречия путём семантической конверсии превращаются в темпоральные, например:

авар. хадуб, агул. хав(ди), дарг. гІелаб, лак. махъ, лезг. кьулухъ, карат. хиги, рутул. хъуъна «позади» (пространство) и «после» (время);

авар. иебе, агул. уригь(ди), дарг. гъалаб, лак. хьхьичI, лезг. вилик карат. сиги, чамал. $с с u^{\text {н } ~ « в п е р е-~}$ ди» (пространство) и «до, перед», «раньше» (время).

Пространственные отношения трансформируются во временные посредством суффиксации, например: авар. ицебе «впереди» $\rightarrow$ ициебего (ицебе + го) «давно»; агул. уригь «впереди» $\rightarrow$ уригьди $(y р и г ъ+\partial u)$ «прежде», чамал. ссино «спереди» $\rightarrow$ ссинодаал (ссино $+\partial a+a \pi)$ «с самого начала»; карат. ссиги «впереди» $\rightarrow$ ссигида (сиги + да) «давно» и т.д.

Примеры, авар.:

Нежер рукъалда ицебе ах буго. «Перед нашим домом сад (есть)».

Дида гъеб ах ицебего бихьичІо. «Я этот сад давно не видел».

Линейное время в дагестанских языках концептуализируется также посредством дейктических (указательных) местоимений. Для дагестанских языков характерна разветвлённая система дейктических местоимений, репрезентирующих семантику локализации объекта относительно говорящего (субъекта) в различной удалённости от него как по горизонтали, так и по вертикали. Количество таких местоимений в разных языках колеблется от трёх до тринадцати. Наименьшее количество (3) представлено в цезской подгруппе аваро-андо-цезских языков и в ряде лезгинских языков. Наибольшее количество (13) - в языках андийской подгруппы аваро-андо-цезских языков (каратинском и чамалинском). Для большинства дагестанских языков характерна пятичленная система указательных местоимений, выражающих удалённость от говорящего по вертикали (авар. лъоб, дарг. икI, лак. кIa «тот, выше уровня говорящего»; авар. гъоб, дарг. их, лак. га «тот, ниже уровня говорящего») и по горизонтали (авар. гъаб, дарг. ищ, лак. ва «этот, рядом с говорящим»; авар. гвеб, дарг. ил, лак. та «этот, одинаково удалённый от говорящего и слушающего»; авар. доб, дарг. um, лак. му «тот, вдали от говорящего по горизонтали, рядом со слушающим»).

Для концептуализации времени используются только дейктические местоимения, выражающие удалённость по горизонтали, например: авар. гъаб «этот (рядом с говорящим)»- гъаб заман «настоящее время», гъаб къо «настоящий день»; доб «тот, вдали от говорящего по горизонтали»доб заман «то, прошедшее время», доб къо «тот, прошедший день», например:

Гваб мина дир вациассул буго. «Это (рядом говорящим, на одинаковом уровне с ним) дом моего брата».

Гваб къо дида киданиги кІочон теларо. «Этот (настоящий) день я никогда не забуду».

Доб мина дир инссул буго. «Тот (вдали от говорящих по горизонтали) дом моего отца».

Доб заман иІакъ захІматаб букІана. «То (прошедшее) время было очень трудным».

В даргинском языке временные наречия также образуются только от указательных местоимений горизонтальной ориентации $u \varkappa$, ил, um, посредством присоединения к ним сложного суффикса -хІе-ли: ишхІели «нынче», «сегодня», «в данное время»; илхІели «тогда», «в это (извест- 
ное для слушающего) время» и итхІели «тогда», «в то (известное для коммуникантов) время». Указательные местоимения вертикальной ориентации: $u \kappa I$, $u x$ не участвуют в образовании наречий времени. В даргинском языке в образовании наречий времени и места первостепенную роль играют указательные дейктонимы (местоимения) [1, с. 222].

Подобные темпоральные наречия во всех дагестанских языках образуются от дейктических местоимений. Средства образования наречий времени могут различаться: в даргинском для этого используется суффиксальный комплекс - хIе-ли, в аварском - имена существительные темпоральной семантики сагIam «час» (для настоящего времени) и мех «время» (для прошедшего времени).

Другим источником образования темпоральных наречий служат наречия места. Один из способов образования темпоральных наречий в дагестанских языках - это сочетание двух наречий места: авар. ицебе-нахъа, лак. хьхьичI-махъ, карат. ссиги-хиги «1. рано или поздно, когда-нибудь; 2. иногда», букв. «впереди-позади»; авар. гьоркьо-гьоркьоб «иногда», букв. «в середине-середине», «между-между», андал. диал. кьоро-гІодоб «иногда», букв. «между-внизу» (кьороб «между»гІодоб «внизу»); лак. утти-гъанну «недавно», букв. «теперь близко» (утти «теперь» - гъанну «близко»); авар. гъанже гІагарда «в ближайшее время», букв. «сейчас-рядом» (гъанже «сейчас» гІагарда «рядом»), карат. хирхи-ссисир «подряд» (хирхи «следом» + ссиги «впереди»); бакьи-ссиги «изредка» (бакьи «между» + ссиги «впереди») и т.д. При образовании сложных наречий времени от наречий места пространственные значения трансформируются во временные. В чамалинском языке П.Т. Магомедова также выделяет сложные наречия времени, образованные от наречий места: гъикьанода-ахи «с самого начала» (гьикьанода «снизу» + ахи «наверх»), синода-ал «с самого начала» (синода «спереди»-ал «сюда») и др. [5, с. 97].

Анализ лексики, репрезентирующей субстанциональное время в дагестанских языках, позволяет утверждать, что пространственные представления служат базой для формирования темпоральной картины мира.

Можно представить путь развития временных представлений в виде схемы: (1) антропоцентрически обусловленные пространственные представления > (2) пространственно-временные представления > (3) временные представления, не связанные с пространством.

В сознании человека, воспринимающего реальное время, сочетаются два фактора: 1) объективный фактор - отражение реального мира таким, каким он есть, который обуславливает универсальные, общие для всех языков понятийные категории; 2) субъективный фактор - этноспецифическое субъективное отношение к миру, который формирует различия в репрезентации данных категорий.

Локализация одного и того же темпорального отрезка в одних языках перед временным ориентиром, а в других - позади данного ориентира объясняется идиоэтноспецификой вербализации времени в языках различных этнических культур.

Для концептуализации аналогичных временных отрезков одни языки применяют горизонтальную локализацию (корреляция «впереди» «позади»), другие - вертикальную (корреляция «над» «под»). Концептуализация времени посредством различных пространственных параметров характерна как для линейного, так и для циклического времени.

Структурная организация и семантическое наполнение наречий времени наиболее наглядно репрезентируют специфику вербализации времени в языках различных культур и традиций.

Семантическая конверсия является распространённым средством превращения локальных наречий («позади», «впереди» и др.) в темпоральные («после», «до», «перед» и т.д.) в большинстве языков и свидетельством тесной связи пространства и времени.

Тот факт, что дагестанские языки по-разному (впереди, позади, над, под) локализуют одну и ту же темпоральную семантику, свидетельствует о том, что Дагестан - это не только «гора языков», но и «мозаика культур».

(C) Маллаева 3.М., Халидова Р.Ш., 2021 


\section{Список литературы}

1. Абдуллаев 3.Г. Даргинский язык. 2. Морфология / 3.Г. Абдуллаев. М.: Наука, 1993. 473 с.

2. Блэк М. Лингвистическая относительность (Теоретические воззрения Б.Л. Уорфа) // Новое в лингвистике. Вып. 1. М., 1960. C. $199-212$.

3. Булыгина Т.В. Языковая концептуализация мира (на материале русской грамматики)./ Т.В. Булыгина, А.Д. Шмелёв. M., 1997. 577c.

4. Гамзатов Г.Г. Язык - душа и имя народа // Языки Дагестана. Махачкала - Москва, 2000. С. 13-17.

5. Магомедова П.Т. Образование наречий времени в чамалинском языке // Выражение временных отношений в языках Дагестана. Махачкала: ИЯЛИ ДНЦ РАН, 1991. С. 93-98.

6. Маллаева 3.М. Взаимосвязь терминов пространственной и временной ориентации по материалам аварских диалектов // Диалектологическое изучение дагестанских языков. Махачкала: ИЯЛИ ДНЦ РАН, 1992. С. 41-44.

7. Маллаева 3.М. Темпоральная лексика аварского языка // Временные отношения в дагестанских языках. Махачкала: ИЯЛИ ДНЦ РАН, 1991. С. 77-86.

8. Мельников Г.П. Принципы и методы системной типологии языков: Дис. док. филол. наук: 10.02.20 /ВКИМО. М., 1990. T.1. $406 \mathrm{c}$.

9. Мельников Г.П. Лингвистика, антропология и проблема интеллектуальных потенций // Proceeding of the XV World Congress of Philosophy (17-th to 22-nd September 1973. Varna (Bulgaria). Vol. 5). Sofia, 1974. P. 463-466.

10. Тарланов 3.К. Проблемы общей грамматики и грамматики агульского языка / 3.К. Тарланов. Махачкала: ИЯлИ ДНЦ PAH, 2013. 392 c.

11. Уорф Б.Л. Отношение норм поведения и мышления к языку // Новое в лингвистике. Вып. 1. М., 1960. С. 183-198.

12. Хайдаков С.М. Сравнительно-сопоставительный словарь дагестанских языков / С.М. Хайдаков. М.: Наука, 1973. $180 \mathrm{c}$.

13. Чугунова С.А. Концептуализация времени в разных культурах. Дисс. доктора филологических наук, 2009, [Электронный ресурс] - URL:https://www.dissercat.com/content/kontseptualizatsiya-vremeni-v-raznykh-kulturakh. (Дата доступа 25.03.2021)

14. Bybee J.L. The Evolution of Grammar: Tense, Aspect and Modality in the Languages of the World / J.L. Bybee, R.D. Perkins, W. Pagliuca. Chicago: Univ-ty of Chicago Press, 1994. 420 p.

15. Evans V. The Structure of Time. Language, meaning and temporal cognition / V. Evans. Amsterdam; Philadelphia: John Benjamin's Publ. Company. 2004. 287 p.

16. Jespersen O. Syntax. Time and Tense. A Modern English Grammar on historical principles. Part IV / O. Jespersen. Copenhagen: Munksgaard, $1931.400 \mathrm{p}$.

\section{Сокращения}

$$
\begin{aligned}
& \text { авар. - аварский язык } \\
& \text { агул. - агульский язык } \\
& \text { арч. - арчинский язык } \\
& \text { ахв. - ахвахский язык } \\
& \text { дарг. - даргинский язык } \\
& \text { лак. - лакский язык } \\
& \text { лезг. - лезгинский язык } \\
& \text { карат. - каратинский язык } \\
& \text { рутул. - рутульский язык } \\
& \text { чамал. - чамалинский язык } \\
& \text { таб. - табасаранский язык }
\end{aligned}
$$

\section{References}

1. Abdullaev, Z.G. Darginskii iazyk. 2. Morfologiia [Dargin Language. Morphology] / Z.G. Abdullaev. Moscow: Nauka, 1993. $473 \mathrm{p}$.

2. Black, M. Lingvisticheskaia otnositel'nost' (Teoreticheskie vozzreniia B.L. Worfa) [Linguistic relativity: The views of Benjamin Lee Whorf] // Novoe v lingvistike. Vyp. 1. Moscow, 1960. S. 199-212.

3. Bulygina, T.V., Shmelev, A.D. Iazykovaia kontseptualizatsiia mira (na materiale russkoigrammatiki) [Linguistic conceptualization of the world (based on Russian grammar)] / T.V. Bulygina, A.D. Shmelev. Moscow, 1997. 577s.

4. Gamzatov, G.G. Iazyk - dusha i imia naroda [Language is the Soul and Name of the People] // Iazyki Dagestana. Makhachkala Moscow, 2000. P. 13-17.

5. Magomedova, P.T. Obrazovaniie narechii vremeni v chamalinskom iazyke [Formation of Adverbs of Time in the Chamalin Language] // Vyrazhenie vremennykh otnoshenii v iazykakh Dagestana. Makhachkala: IIALI DNC RAN, 1991. P. 93-98.

6. Mallaeva, Z.M. Vzaimosviaz' terminov prostranstvennoi i vremennoi orientatsii po materialam avarskikh dialektov [Interrelation of Terms of Spatial and Temporal Orientation Based on Materials of Avar Dialects] // Dialektologicheskoe izuchenie dagestanskikh iazykov. Makhachkala: IIALI DNC RAN, 1992. P. 41-44. 
7. Mallaeva, Z.M. Temporal'naia leksika avarskogo iazyka [Temporal Vocabulary of the Avar Language] // Vremennye otnosheniia v Dagestanskikh iazykakh. Makhachkala: IIALI DNC RAN, 1991. P. 77-86.

8. Mel'nikov, G.P. Printsipy i metody sistemnol tipologii iazykov [Principles and methods of systemic typology of languages] / G.P. Mel'nikov Dis. dok. filol. nauk: 10.02.20 /VKIMO. M., 1990. T.1. 406 s.

9. Mel'nikov, G.P. Lingvistika, antropologiia i problema intellektual'nykh potentsii [Linguistics, Anthropology and the Problem of Intellectual Potencies] // Proceeding of the XV World Congress of Philosophy (17-th to 22-nd September 1973. Varna (Bulgaria). Vol. 5). Sofia, 1974. P. 463-466.

10. Tarlanov, Z.K. Problemy obshchei grammatiki i grammatiki agul'skogo iazyka [Problems of General Grammar and Grammar of the Agul Language] / Z.K. Tarlanov. Makhachkala: IIALI DNC RAN, 2013. 392 p.

11. Whorf, B.L. Otnoshenie norm povedeniia i myshleniia $k$ iazyku [The Relation of Habitual Though and Behavoir to Language] // Novoe v lingvistike. Vyp. 1. Moscow, 1960. P. 183-198.

12. Khaidakov, S.M. Sravnitel'no-sopostavitel'nyi slovar' dagestanskikh iazykov [Comparative Dictionary of Dagestan Languages] / S.M. Haidakov. Moscow: Nauka, 1973. 180 p.

13. Chugunova, S.A. Kontseptualizatsia vremeni v raznykh kul'turakh. [Conceptualization of time in different cultures] / S.A. Chugunova Diss. doktora filologicheskikh nauk, 2009, www.dissercat.com/ content/kontseptualizatsiya-vremeni-v-raznykhkulturakh (Accessed 25.03.2021)

14. Bybee, J.L. The Evolution of Grammar: Tense, Aspect and Modality in the Languages of the World / J.L. Bybee, R.D. Perkins, W. Pagliuca. Chicago: Univ-ty of Chicago Press, 1994. 420 p.

15. Evans, V. The Structure of Time. Language, meaning and temporal cognition / V. Evans. Amsterdam; Philadelphia: John Benjamin's Publ. Company. 2004. 287 p.

16. Jespersen, O. Syntax. Time and Tense. A Modern English Grammar on historical principles. Part IV / O. Jespersen. Copenhagen: Munksgaard, 1931. $400 \mathrm{p}$.

\section{Сведения об авторах:}

Маллаева Зулайхат Магомедовна - доктор филологических наук, профессор, главный научный сотрудник ИЯЛИ ДФИЦ РАН (Россия, Махачкала). Сфера научных и профессиональных интересов: лингвистическое кавказоведение, сравнительная типология кавказских и германских языков, аваро-андийские языки, синтаксический строй дагестанских языков, глагол, категория локализации. E-mail: logika55@mail.ru

Халидова Рашидат Шахрудиновна - доктор филологических наук, профессор, заведующий кафедрой теории и методики обучения русскому языку и литературе ФГБОУ ВО «Дагестанский государственный педагогический университет» (Россия, Махачкала). Сфера научных и профессиональных интересов: лингвистическое кавказоведение, лексика аваро-андийских языков, методика преподавания русского языка, русский язык и культура речи. Email: rashi-dr@mail.ru

\section{About the authors:}

Zulaikhat M. Mallaeva - Doctor of Philology, professor, chief research fellow at the Institute of Language, Literature and Art, Dagestan Centre of Sciences (DCS), of the Russian Academy of Sciences (RAS). (Makhachkala, Russia). Spheres of research and professional interests: linguistic Caucasian studies, comparative typology of Caucasian and Germanic languages, Avar-Andy languages, syntactical system of Dagestanian languages, the verb, the category of localization. E-mail: logika55@mail.ru

Rashidat Sh. Khalidova - Doctor of Philology, Professor, Head of the Chair of Theory and Methodology of the Russian Language and Literature at Dagestan State Pedagogical University (Makhachkala, Russia). Spheres of research and professional interests: linguistic study of the Caucasian languages, lexis of Avar-Andi languages, methods of teaching the Russian Language, the Russian language and speech culture. E-mail: rashi-dr@mail.ru 